\title{
The Compact Irradiator Modulus Designed for DNA Repair and Mutagenesis Studies in ISS Microgravity Environment Using UVA Emitted by Light-Emitting Diodes
}

\author{
Marcelo Sampaio ${ }^{1}$, Heitor Evangelista², Roberto d'Amore ${ }^{3}$, Nasser Ribeiro Asad², Lídia Maria

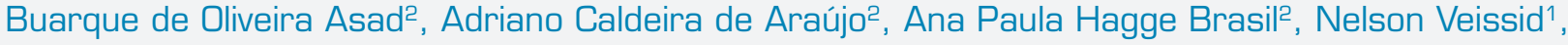 \\ Valeri Vlassov ${ }^{1}$, Alessandra Pacini ${ }^{4}$, Monique Thérèze Schulz Fontoura²
}

\begin{abstract}
This work presents the design and characteristics of a new compact ultraviolet (UV) irradiator used in a biological onboard space flight experiment. The experiment, called DRM, took place in the International Space Station research facility (ISS-13 expedition), during the Centenary Mission (Russian-Brazil) in March-April 2006. The DRM main objective was to correlate the DNA repair mechanism and mutagenesis with microgravity. A compact irradiator apparatus was designed for DRM to allow in situ induced radiation in space. This apparatus, called CIM, uses UV-A Light-emitting diodes (LEDs) with $375 \mathrm{~nm}$ wavelength as molecular lesions inducers on four bacterial $E$. coli strains. The manned space mission restrictions were focused on during the CIM main parts design. The ultraviolet dosimetry is also described in this document as DRM experiment results and the CIM operational data are reported to certify the CIM design and DRM protocol compatibility in space application.
\end{abstract}

KEYWORDS: Ultraviolet radiation, Microgravity, ISS.

\section{INTRODUCTION}

During the last decades, experiments using different bacteria (e.g.: Bacillus subtilis HA 101, Echerichia coli $\mathrm{B} / \mathrm{r}$, Echerichia coli $\mathrm{PQ} 37$, Echerichia coli $3 \mathrm{cp}$, Deinococcus radiodurans type $\mathrm{R}$, Deinococcus radiodurans type $\mathrm{R}+\mathrm{rec} 30$ ) have been conducted and their preliminary conclusions point to no significant statistical difference existing in DNA repair mechanism responses to equivalent radiation doses under microgravity or terrestrial conditions. These experiments have been developed under an approximately common basic protocol: essentially, they have used facilities of irradiation on Earth (e.g.: employing X-ray, gamma ray or UV-C radiation) to achieve a large spectrum of dose responses, followed by cooling and transportation to the microgravity environment, where the samples were incubated under controlled temperatures, ranging normally from $+20^{\circ} \mathrm{C}$ to $+37^{\circ} \mathrm{C}$, depending on the experiment type and organism employed. In these conditions, the biological systems are available to repair damages in the DNA from naturally occurring and artificially induced radiation. After a period of time in space, they were cooled again and sent back to the Earth's surface, where their results were compared with ground controls. One exception was the in situ space irradiation experiment, conducted by Pross et al. (2000) during the Shuttle Atlantis flight STS-84. The experiment employed a ${ }^{63} \mathrm{Ni}$ beta source to irradiate diploid mutant rad54-3 of the yeast Saccharomyces

\footnotetext{
1. Instituto Nacional de Pesquisas Espaciais - São José dos Campos/SP - Brazil 2.Universidade do Estado do Rio de Janeiro - Rio de Janeiro/RJ - Brazil 3.Instituto Tecnológico de Aeronáutica - São José dos Campos/SP - Brazil 4. Universidade do Vale do Paraíba - São José dos Campos/SP - Brazil. 
cerevisiae. They also concluded that no significant difference was observed for either induction or repair but due to the type of radiation used in the experiment, their conclusion was restricted to double-strand breaks. Table 1 shows a brief compilation of space flight experimental conditions employing studies of DNA repair and mutagenesis.

An alternative method to achieve higher dose levels over the biological material in space flights, without using artificial sources aboard, is the external exposition of the biological experiment, as performed during the EXOBIOLOGIE experiment that belonged to the French PERSEUS mission (1999) onboard the MIR station (Rettberg et al., 2002). The authors investigated the ability of microorganisms (spores of the B. subtilis DNA repair, wild-type strain (HA 101X) and a DNA-repair deficient mutant strain (TKJ 6312, uvr.4Zf.Js pl-1)) to survive high doses of extraterrestrial solar UV alone or in combination with other space parameters (e.g. vacuum, microgravity, and cosmic radiation). They reported the protective effects over microorganisms of inorganic substances like artificial or real meteorites (in a powdered state).

Other microbiological experiment compilations which discuss ionized radiation conducted in Low Earth Orbit (LEO) can also be found at Olsson-Francis and Cockell (2010). If, on the one hand, there is acceptable evidence that weightlessness alters several cellular functions and effects signaling pathways associated to cell proliferation, differentiation and death (Manti, 2006), its effective influence on DNA repair still raises controversies, despite an apparent trend to invariance between ground and space results. Kiefer and Pross (1999) concluded that the radiation repair is not impaired by the space environment and, based on the premise that the repair mechanism appears to be evolutionarily conserved, they further argued that it also holds true for mammalian cells. Nevertheless, direct comparison of onboard and terrestrial experimental results still presents important constraints: the interaction of the total spectra of cosmic ionizing radiation with an organism is not fully simulated on the ground, especially in the case of HZE particles, the ones with $\mathrm{Z}>2$. They are $\sim 1 \%$ of the total galactic cosmic radiation with energies high enough to penetrate at least $1 \mathrm{~mm}$ of the spacecraft walls. HZE particles may represent up to $50 \%$ of the effective dose in space (Ottolenghi et al., 2001). Their contribution of the radiation derived from the by-products originating from collisions of the cosmic rays primary beams with the nuclei of the materials which compose the spacecraft shielding.

In the history of radiobiological experiments in space, the use of onboard radiation sources occurred between the Gemini 3
Mission and the Spacelab D1 Mission, the results of which were reported between 1967 and 1986 (Kiefer and Pross, 1999). In this period, the onboard experiments used gamma ray radiation point sources that produced doses varying from 60 to $1,600 \mathrm{~Gy}$, and beta radiation of ${ }^{32} \mathrm{P}$ and ${ }^{85} \mathrm{~S}$. These experiments focused on alterations in the chromosomal or hematopoietic tissue, formed by fibers and cell types that support the blood tissue-forming cells (stem cells). Nevertheless, restrictions were imposed on the use of these manufactured ionizing radiation sources, which may generate high doses and high dose rates onboard during space missions, since their use could result in increased risks to the crew members. The use of ultraviolet lamps also created safety problems due to their toxic vapor contents. More recently, when there has been a surge of techniques that would significantly improve our knowledge of space biology responses to space radiation, through molecular level research, most radiobiological protocols have still been limited to preflight irradiation conditions. A promising alternative to that is the use of unmanned, free-flying nanosatellites, like the SESLO experiment during the Space Environment Organism/Organic Exposure to Orbital Stresses (O/OREOS), mission (Nicholson et al. 2011). The mission was launched to a $650 \mathrm{~km}$ Earth orbit, providing a total dose rate in the experiment 15 times higher than observed at the ISS (exposed to microgravity, ionizing radiation, and heavy-ion bombardment due to its high-inclination orbit), using living organisms (B. subtillis wild-type 168 and radiation-sensitive mutant $\mathrm{WN} 1087$ strains).

In view of the above limitations, we have developed the DRM (DNA Repair Under Microgravity) experiment to observe the biological response at the molecular level due to the combination of naturally occurring cosmic radiation and induced UV-A. We have developed a portable, hermetic UV-A irradiator, based on UV-A LED technology to conduct the DRM experiment, the Compact Irradiator Modulus (CIM). Here the UV-A irradiation was used in order to just enhance the biological response (not because it is significant for space missions) and observe if any synergistic response would occur in the presence of cosmic radiation. The equipment allowed for the study of the DNA repair and mutagenesis of E. coli K12 strains in conditions of irradiation in space (International Space Station-ISS $/ 13^{\text {th }}$ mission), during the Centenary Space Mission (Brazil-USA-Russian) in March-April 2006. Here we describe the CIM apparatus and the DRM experiment procedures and results. We have also characterized the space weather conditions during the experiment. 
Table 1. A brief summary of recent radiobiological studies involving DNA repair in bacteria, yeast and human lymphoblastoid during flight missions.

\begin{tabular}{|c|c|c|c|c|c|}
\hline Biological system & Type of radiation & $\begin{array}{c}\text { Site of } \\
\text { irradiation }\end{array}$ & Dose & $\begin{array}{l}\text { Flight payload; } \\
\text { Mission }\end{array}$ & Reference \\
\hline Saccharomyces cerevisiae & $\mathrm{X}$-ray, $80 \mathrm{kV}$ & Ground & $>140 \mathrm{~Gy}$ & STS-42; IML-1 & Pross et al., 1994 \\
\hline Bacillus subtilis & UV-C, $254 \mathrm{~nm}$ & Ground & $>335 \mathrm{~J} \mathrm{~m}^{-2}$ & STS-65; IML-2 & Horneck et al., 1996 \\
\hline Escherichia coli B/r & $\mathrm{X}$-ray, $150 \mathrm{kV}$ & Ground & $120 \mathrm{~Gy}$ & STS-65; IML-2 & Horneck et al., 1996 \\
\hline Escherichia coli PQ37 & Gamma ray, ${ }^{60} \mathrm{Co}$ & Ground & $300 \mathrm{~Gy}$ & STS-65; IML-2 & Horneck et al., 1996 \\
\hline Deinococcus radiodurans & Gamma ray, ${ }^{60} \mathrm{Co}$ & Ground & 2-12 kGy & STS -65; IML-2 & Kobayashi et al., 1996 \\
\hline Saccharomyces cerevisiae & $\mathrm{X}$-ray, $80 \mathrm{kV}$ & Ground & $140 \mathrm{~Gy}$ & STS-76; SMM-03 & Pross and Kiefer, 1999 \\
\hline Deinococcus radiodurans & Gamma ray, ${ }^{60} \mathrm{Co}$ & Ground & $1-12 \mathrm{kGy}$ & STS 79 & Kobayashi et al., 2000 \\
\hline Saccharomyces cerevisiae & Beta ray, ${ }^{63} \mathrm{Ni}$ & Space & Not mentioned & STS 84 & Pross et al., 2000 \\
\hline Escherichia coli KY396 & $\begin{array}{l}\text { X-ray, } 150 \mathrm{kV} \text { and } \\
\text { UV-C, } 254 \mathrm{~nm}\end{array}$ & Ground & $\begin{array}{l}150 \mathrm{~Gy} \text { and } \\
2 \mathrm{~J} \mathrm{~m}^{-2}\end{array}$ & STS-91 & Takahashi et al., 2001 \\
\hline Saccharomyces cerevisiae & UV-C, $254 \mathrm{~nm}$ & Ground & $30-300 \mathrm{~J} \mathrm{~m}^{-2}$ & STS-91 & Takahashi et al., 2001 \\
\hline Saccharomyces cerevisiae & $\mathrm{X}$-ray, $150 \mathrm{kV}$ & Ground & $100-750$ Gy & STS-91 & Takahashi et al., 2001 \\
\hline Saccharomyces cerevisiae & $\mathrm{X}$-ray, $150 \mathrm{kV}$ & Ground & 100-750 Gy & STS-91 & Takahashi et al., 2001 \\
\hline $\begin{array}{l}\text { Spores of the Bacillus } \\
\text { subtilis wildtype strain (HA } \\
\text { 101X) and DNA-repair } \\
\text { deficient mutant strain } \\
\text { (TKJ 6312, uvrA10 spl-1) }\end{array}$ & $\begin{array}{l}\text { Full extraterrestrial } \\
\text { UV spectrum }\end{array}$ & Space & 36.8-48.7 mGy & $\begin{array}{l}\text { MIR; } \\
\text { EXOBIOLOGIE/ } \\
\text { Perseus }\end{array}$ & Rettberg et al., 2002 \\
\hline $\begin{array}{l}\text { Deinococcus radiodurans } \\
\text { and Bacillus sp. (PS3D) }\end{array}$ & Extreme UV, $30.4 \mathrm{~nm}$ & Space & $\begin{array}{c}6 \times 10^{16} \\
\text { photons } \mathrm{m}^{-2}\end{array}$ & $\begin{array}{l}\text { Terrier Black Brant } \\
\text { rocket; SERTS }\end{array}$ & Saffary et al., 2002 \\
\hline $\begin{array}{l}\text { Wild type Saccharomyces } \\
\text { cerevisiae strain } \\
\text { (ATCC 18824) }\end{array}$ & $\begin{array}{l}\text { Satellite environment } \\
\text { radiation / } \\
\text { Not provided }\end{array}$ & Space & Not mentioned & $\begin{array}{c}\text { Practice } 8 \\
\text { recoverable satellite }\end{array}$ & Yi et al., 2011 \\
\hline $\begin{array}{l}\text { Human lymphoblastoid } \\
\text { cell lines: TSCE5 (wtp53 } \\
\text { gene status) and WTK1 } \\
\text { (mp53 gene status) }\end{array}$ & $\begin{array}{l}\text { Full extraterrestrial } \\
\text { radiation spectrum }\end{array}$ & Space & $71.2 \mathrm{mSv}$ & ISS & Takahashi et al., 2011 \\
\hline $\begin{array}{c}\text { Bacillus subtilis (wild-type } \\
168 \text { and and mutant } \\
\text { WN1087) }\end{array}$ & $\begin{array}{l}\text { Satellite environment } \\
\text { radiation } \\
\text { (650 km Earth orbit) }\end{array}$ & Space & 1.0-1.6 Gy & $\begin{array}{c}\text { O/OREOS } \\
\text { nanosatellite }\end{array}$ & Nicholson et al. 2011 \\
\hline $\begin{array}{c}\text { Human lymphoblastoid } \\
\text { TK6 cells }\end{array}$ & $\begin{array}{l}\text { Full extra-terrestrial } \\
\text { radiation spectrum }\end{array}$ & Space & $54 \mathrm{mSv}$ & ISS & Yatagai et al., 2012 \\
\hline
\end{tabular}

STS: Space Shuttle Missions.

A specific hardware was designed owing to attend the experiment, the specifications and flight restrictions: weight, dimensions, biological barriers protocols and temperature safety limits. The bacterial samples were isolated in slots wile being irradiated. Each slot is submitted to the environmental cosmic radiation and induced UV-A radiation generated by an array of $18 \mathrm{UV}$-A $375 \mathrm{~nm}$ LEDs. The use of UV-A LEDs in compact biological experiments presented several advantages: it promotes 
a closer contact of the biological material with the irradiation sources improving the dosimetric model; the geometry of each radiation slot as a small rectangular hermetically closed box resulted in a relatively well distributed dose to the biological material inside them; UV-A LED generates $375 \mathrm{~nm}$ irradiation with $10 \mathrm{~nm}$ bandwidth, at full spectrum half width. They are more resistant to vibration than conventional lamps.

Unlike the previous experiments, the CIM made it possible to irradiate the bacterial strains with a predetermined dose of radiation while in the microgravity of space. Thus, it was possible to carry out both irradiation and cell repair in the same environment without having to manipulate the biological material in the confined environment of the spacecraft. Therefore, it is a new experimental process.

\section{REQUIREMENTS AND TECHNICAL CONSTRAINTS}

The CIM apparatus was transported to the ISS by the Soyuz TMA-8 spacecraft. Once onboard the ISS, it was operated in the Russian Segment (RS) of the space station before returning to Earth aboard Soyuz TMA-7 on April 9, 2006.

The requirements and constraints imposed on biological experiments onboard the space shuttles (Cogoli,1996) are basically the same as those of the ISS/Soyuz. The CIM design takes into account all of the safety restrictions of this manned satellite, the Soyus-TMA transport limitations, and the established conditions for the DRM project (SSP41163, 1999; SSP50094, 2000; SSP50146, 1998). The CIM was powered by a DC power supply of the ISS module power supply system (PSS), with a $28.5 \pm 0.5 \mathrm{VDC}(3 \mathrm{~A})$ nominal voltage. The mass was limited to $3 \mathrm{~kg}$ for transport aboard the Soyuz to the ISS and to $1.5 \mathrm{~kg}$ for the return. Using the appropriate LINS (Line Impedance Stabilization Network), the conducted electromagnetic emissions were found to be between 10 and $100 \mathrm{~Hz}$, and the radiated electromagnetic emissions emitted during CIM operation were between $10 \mathrm{kHz}$ and $1000 \mathrm{MHz}$. The integrity of the characteristics and the functioning of the CIM system were checked to comply with the expected pressure, temperature, and humidity constraints of the Soyuz and ISS environments. Several Environmental Compatibility requirements had to be met: touch temperature exposed parts; off-gassing (a quantitative analysis of gases that may be generated by non-metallic materials); biological barriers (the guarantee of containment of biological material); external characteristics (no sharp edges, corners and shatterable materials are allowed, in order to avoid any injury during microgravity handlings. The fan blades are protected by $3 \mathrm{~mm}$ grid holes); and ergonomy (protection against erroneous operations).

\section{THE COMPACT IRRADIATOR MODULUS (CIM) SYSTEM AND OPERATION}

The total CIM hardware is divided into 4 different modules, as shown in Fig. 1 and Fig. 2: the Irradiator Module, with four slots, loaded with biological material that is irradiated during the DRM experiment; the Fan Module, responsible for maintaining the biological material's proper temperature during irradiation period; the Memory Module, which stores all relevant data; and the Electronics Module that controls the proper functioning of all the equipment. Only the Irradiator Module and the Memory Module return to Earth. All CIM electronic components are Commercial Off-The-Shelf(COTS), except for the DC/DC converters, the Input EMI filter, connectors and the DC power cable.

Irradiator Module (IM): The main body of the IM contains the biological material distributed in four $1 \mathrm{~mL}$ square wells called "Irradiated slots," where the irradiation takes place; four $25 \mu \mathrm{L}$ "background slots", where no irradiation occurs; and one fence, designed to contain two thermoluminescent solid state dosimeters (TLD-100 - LiF : Mg,Ti), used to quantify the environmental ionizing radiation. Each one of the 4 irradiated slots has 18 UV-A LEDs (NICHA Co. model NSHU550A UV-A $375 \mathrm{~nm}$ ) facing its surfaces. The LEDs are distributed over its upper and bottom halves (Fig. 3), containing 9 units on each side. These slots are isolated from the environment by biological barriers that are implemented with silicon and nitrilic rubber o-rings and Scotch Weld ${ }^{\circledR} 2216$ epoxy adhesive.

The Fan Module (FM): When switched on, each UV-A LED dissipated about $35 \mathrm{~mW}$. Therefore, extra thermal power was generated while a total of 72 LEDs were switched on during the experiment. This process was responsible for a temperature increase of the equipment. The FM was designed to be connected to the irradiation module in order to maintain the biological material temperature never above $39^{\circ} \mathrm{C}$; in fact, during the irradiation aboard the ISS, it was always maintained 
The Compact Irradiator Modulus Designed for DNA Repair and Mutagenesis Studies in ISS Microgravity Environment Using UVA Emitted by Light-Emitting Diodes

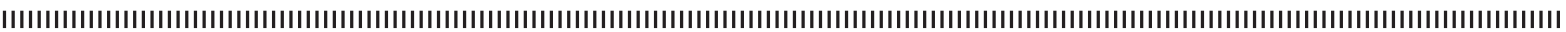

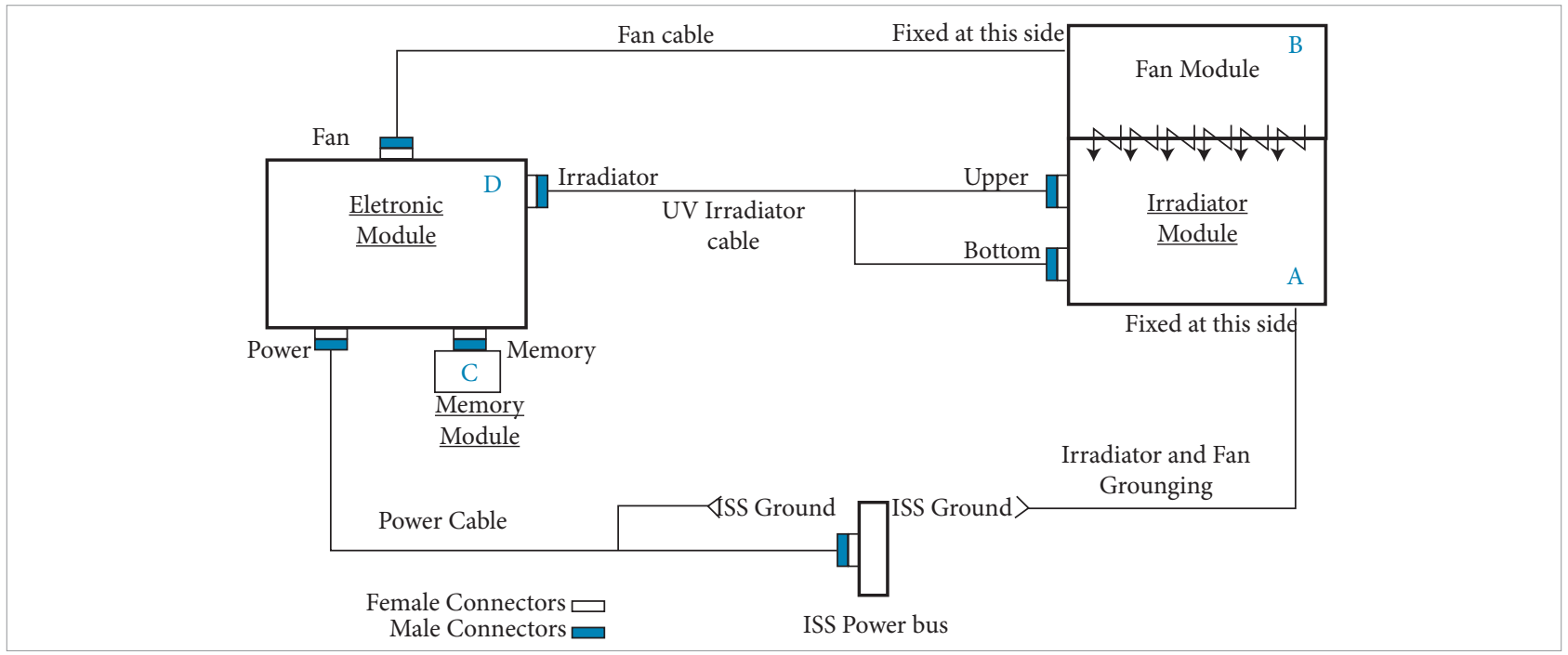

Figure 1. CIM block diagram.

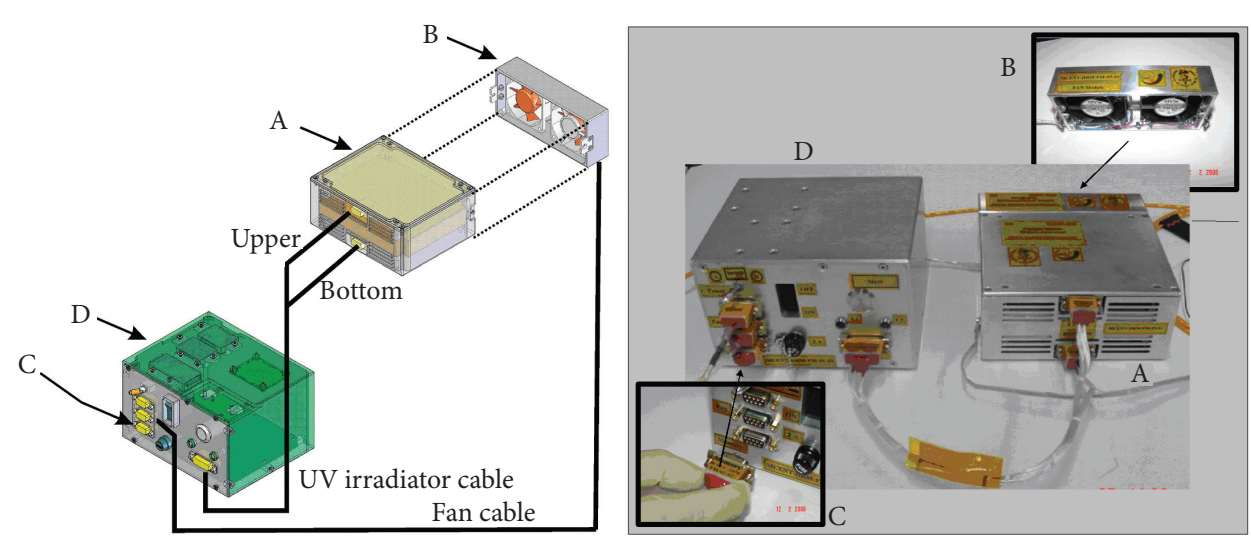

Figure 2. Compact Irradiator Modulus interconnected. (A) Irradiator (IM); (B) Fan (FM); (C) Connector to attach Memory (MM); and (D) Electronic (EM).

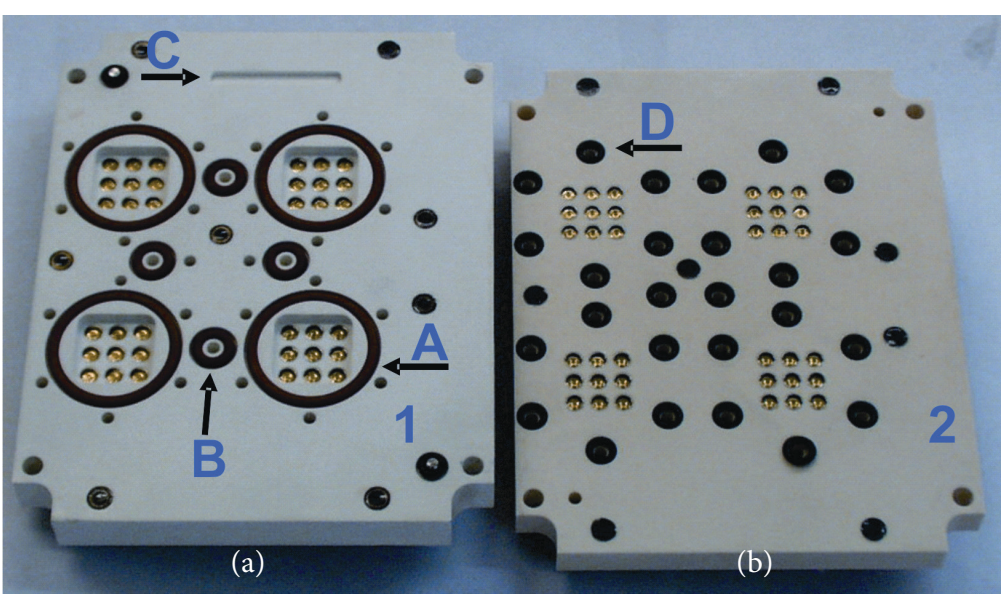

Figure 3. (a) Bottom half; (b) Upper half of inner Irradiator Module. (A) One Irradiated slot with the silicon rubber o'ring; (B) One background slot with the silicon rubber o'ring; (C) Thermoluminescent dosimeter fence; (D) nitrilic rubber o'rings. The screws which fasten the two halves are passed through nitrilic o'rings. The picture presents (4x) 9 UVA LEDs facing the upper half and (4x) 9 LEDs facing the bottom half of the irradiated slot. 
below $30^{\circ} \mathrm{C}$. Convective cooling was generated by two $60 \mathrm{~mm}$ ball bearing type fans (one redundant). Pre-flight temperature controlled tests demonstrated that, while fan cooling was applied, the irradiation slot temperature did not exceed $8^{\circ} \mathrm{C}$ above room temperature, merely reaching an equilibrium with room temperature.

Memory Module (MM): The MM is composed of two serial EEPROM IC memories (one redundant), mounted in a military/high reliability specification connector and encapsulated with a silicone rubber compound. This module is attached to the Electronic Module by a faced external connector (Fig. 2 c). All relevant experiment data is recorded in it. After integration and initialization of the experiment, this module recorded the 8051 firmware status and the following relevant parameters: (1) the temperature within the slots; (2) the temperature of the irradiation module itself; (3) the irradiation status (on/off) and; (4) the voltage values in the memory module. Time resolution of acquisition data was 1 minute. This data was recovered on Earth at the mission's end.

Electronic Module (EM): This module was composed of the 8051 family microcontroller, which commanded both the IM and FM. The power supply used by the fan module was provided by the ISS DC bus. It had two internal DC/DC converters which provided the DC power to all the other modules of the experiment. The ISS safety requirements specify that maximum temperature of any external surface of an experiment device should not exceed $40^{\circ} \mathrm{C}$. To meet this requirement, the aluminum case (alloy AL 6063 T6), used in the EM was deeply anodized in order to increase its heat emissivity (to a depth of not less than 0.82 ). The less dissipating electronics were placed on the bottom-front panel, while the upper part of the irradiator module was loaded with the 5 most dissipating components: two DC/DC converters, two Voltage Regulators, and one EMI Filter (for a total of 7.6 Watts during the irradiation period).

UV: UV-A dosimetry was conducted by measuring the spatial distribution of light intensity inside all irradiation slots, since the bacteria will occupy this volume randomly during the experiment. The irradiation conditioning was simulated by filling up the $1 \mathrm{~mL}$ slot with the same saline solution used in the flight experiment. Parallel planes within the slot composed by the array of 9 LEDs at the upper surface and the same at the bottom of the Irradiator Module were analyzed. UV-A spatial distribution was obtained experimentally by screening the light intensity horizontally and vertically inside the slot, using a photocell covered by a mask with a $1 \mathrm{~mm}$ orifice diameter at its center. This photocell was previously calibrated by a UV-A sensor (ORIEL 70260 Radiant Power Meter and ORIEL 70282 Photodiode Absorber Head, that provide sensitivity between $3 \mathrm{~mW}$ to $300 \mathrm{~mW}$ for a $375 \mathrm{~nm}$ wavelength lighting source). Vertical resolution of each step of measurement was $0.1 \mathrm{~mm}$ and $0.2 \mathrm{~mm}$ for the horizontal axis. Figure 4 depicts the configuration of the isopleths of irradiance at 4 different distances from the LED array (upper or bottom part of the irradiation slot). Taking into account both surfaces with 9 LEDs, we obtain each plane's irradiance distribution. This procedure made it possible to compile a complete description of the UV-A intensity distribution inside the irradiation slot. The statistical analysis of the results is presented in Fig. 5. The median value of this collection is $4.38 \mathrm{~mW}^{-2} \mathrm{~cm}^{-2}$, this value was used as total volume slot irradiance (Sampaio, 2007).

Operation and procedures: Aboard the ISS, the astronaut had to follow the unpacking procedures, assemble the Memory and Fan cables; then interconnect the module cables to the EM, and the power cable to the ISS DC bus. Once it was switched on, the EM firmware started a CIM checkup. The Memory and Fan cables were verified and two LEDs on the EM front panel indicated the test condition. After this automatic test, the UV Irradiation was begun by an astronaut command through an EM front panel pushbutton. The IM with FM attached was $154 \mathrm{~mm}$ in length, $149 \mathrm{~mm}$ wide, and $65 \mathrm{~mm}$ high, weighing $1.45 \mathrm{~kg}$. The EM with MM was $149 \mathrm{~mm}$ x $130 \mathrm{~mm}$ and $100 \mathrm{~mm}$ $(\mathrm{l}, \mathrm{w}, \mathrm{h})$, weighing $1.1 \mathrm{~kg}$. All flight models, including cables, extra fuses and the spare MM, were disposed of in three different Nomex ${ }^{\circledR}$ bags. The overall CIM launch dimensions were $260 \mathrm{~mm}$ x $200 \mathrm{~mm} \times 250 \mathrm{~mm}(\mathrm{l} \mathrm{x} \mathrm{w} \mathrm{x} \mathrm{h})$ and the total mass was $3.08 \mathrm{~kg}$. The return mass was $1.24 \mathrm{~kg}$. During the irradiation period, the maximum CIM consumption was 16.6 W (28 VDC, 0.59 A).

After the irradiation period, the equipment was shut down and disabled. The IM and MM were packaged for return to Earth and all other parts were prepared for disposal.

\section{BACTERIAL STRAINS, TRANSPORT, FLIGHT AND EXPERIMENTAL STRATEGY}

The biological material employed in the experiment was composed of bacterial strains derived from $E$. coli $\mathrm{K} 12$ with the following DNA repair phenotypes: AB1157 (wild type), AB2463 (as AB1157, but recA13 - deficient in the repair by recombination 


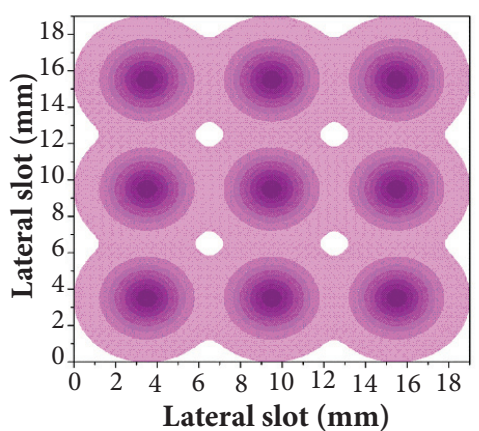

(a)

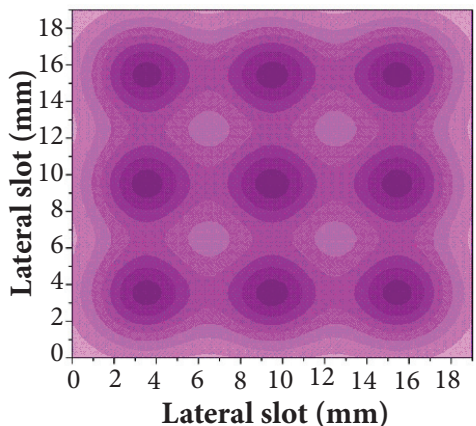

(c)

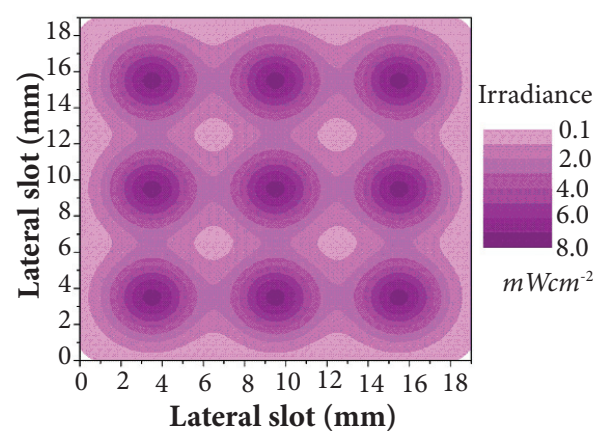

(b)

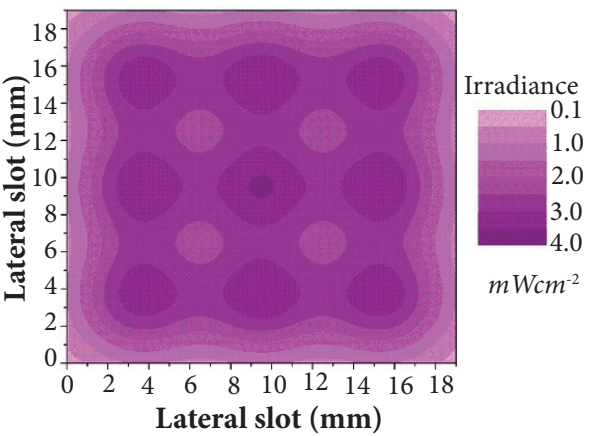

(d)

Figure 4. Isopleths plots for layer irradiance distribution inside one slot: horizontal plane at (a) $0.5 \mathrm{~mm}$ from LED surface; (b) $1.3 \mathrm{~mm}$; (c) $2.1 \mathrm{~mm}$ and (d) $2.9 \mathrm{~mm}$. These layers present partial contribution for one slot surface with 9 LEDs.

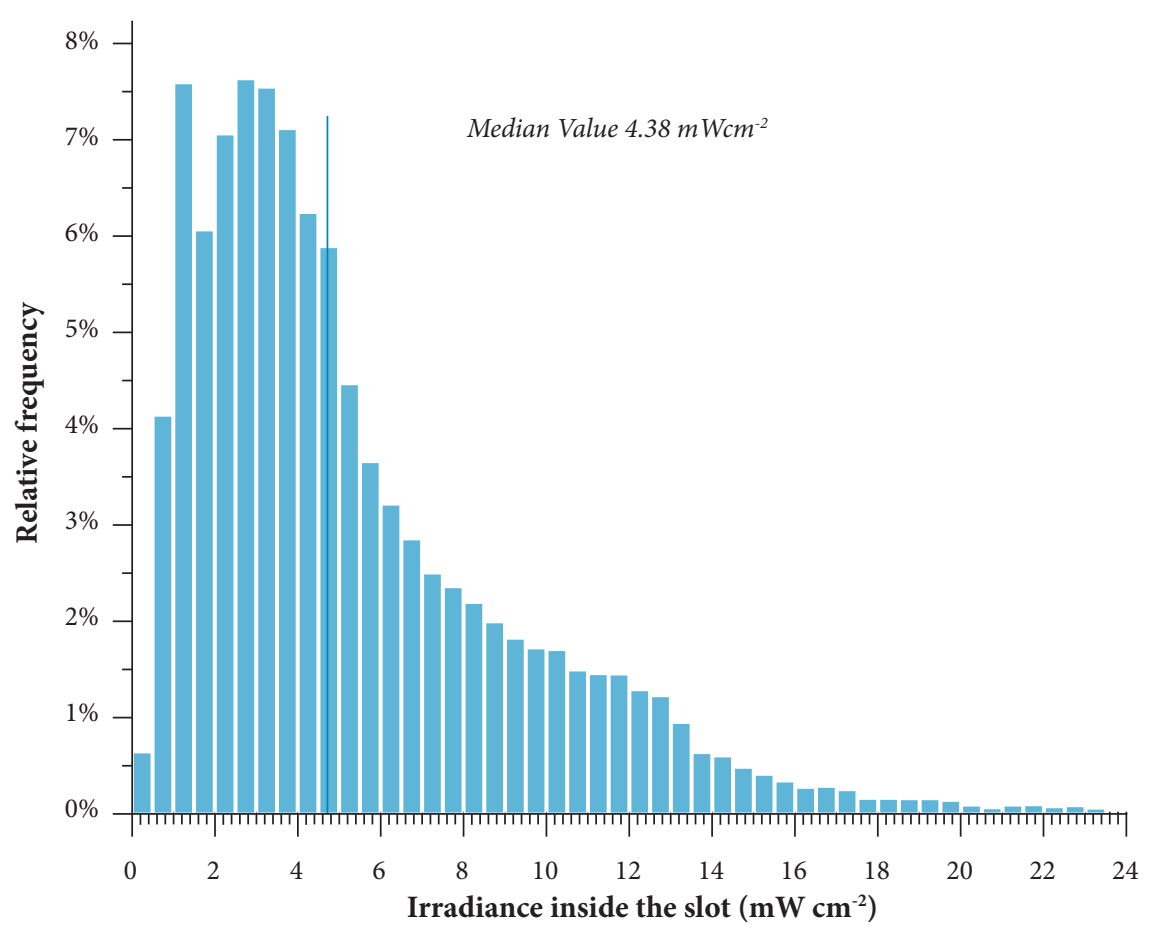

Figure 5. Histogram of Irradiance values inside the irradiated slot. The median value of this collection represents a total slot Irradiance of $4.38 \mathrm{~mW} . \mathrm{cm}^{-2}$. 
and SOS), AB2480 (as AB1157, but uvrA-recA - deficient in nucleotide excision repair, recombination and SOS) and DNA polymerase I deficient strain $\mathrm{P} 3478$, a polA mutant derivative from E. coli wild-type W3110 strain. They were transported from Brazil (Rio de Janeiro State University) directly to the desert of Baykonur (Kazakhstan). The transport was conducted under room temperature and bacterial strains were fixed in Millipore filters of $47 \mathrm{~mm}$ diameter, enclosed in a sterilized plastic holder. In Baykonur, a compact biological laboratory was adapted in an installation of the Russian Flight Center, in order to maintain basic conditions concerning the handling and inoculation of the the biological material in the experimental apparatus.

Figure 6 depicts typical experimental setups for preirradiation (ground irradiation) and onboard irradiation (mostly aboard the ISS, MIR, nanosatellites and Shuttle missions) as indicated in Table 1. The basic difference in protocol steps is where the irradiation takes place. In both cases, it is assumed that the initial phases of the biological repair mechanism occur in microgravity. The inoculation of the biological material took place 6 hours before the launch of the Soyus TMA- 8 spacecraft. On March 29 $9^{\text {th }}$, the biological material was boarded onto the Reentry Module and on March 31 $1^{\text {st }}, 2006$ (02:30 h GMT), Soyus was launched from Baykonur. The experimental apparatus was transferred to the ISS on March $31^{\text {st }}$ and the total period of stay aboard the ISS was 9 days and 12 hours. The equipment was installed and operated close to the air conditioning outflow on the "PIRS docking compartment", between the Zarya and Zvezda modules. Indoor temperature at that site was maintained constant, during the 9 days, at $\sim+21^{\circ} \mathrm{C}$. The apparatus, containing the bacterial strains, returned to Earth on April 9th (GTM: 20:04, April $8^{\text {th }}$ ), using the identification "Module of Biological Urgency" and immediately transported to Moscow/ Russia where it was analyzed, in the same compact biological laboratory once installed in Baykonur. A detailed chronology of the experiment is presented in Table 2.

\section{EXTERNAL RADIATION DOSE AND SPACE WEATHER CONDITIONS DURING THE EXPERIMENT}

Even in low Earth orbits, such as the orbital altitude of the ISS, any biological material is under the influence of Solar Cosmic Rays (SCR) and Galactic Cosmic Rays (GCR), which are formed by particles whose energies vary from $10^{-1}$ to $10^{8} \mathrm{MeV}$. Besides these contributions, trapped particles, especially protons (Reitz et al., 2005), by the Earth's magnetosphere in the Van

Table 2. Chronology of the experiment during the Centenary Mission (March-April 2006)

\begin{tabular}{|c|c|c|c|c|}
\hline Experimental procedure & Date & $\begin{array}{l}\text { Time } \\
\text { GMT }\end{array}$ & $\begin{array}{l}\text { Experiment } \\
\text { chronology }\end{array}$ & $\begin{array}{l}\text { Temperature } \\
\text { amplitude }\end{array}$ \\
\hline Inoculation of bacterial strains in the irradiator in Baykonur & March, $29^{\text {th }}$ & $06: 00 \mathrm{~h}$ & $00: 00 \mathrm{~h}$ & $\sim+25^{\circ} \mathrm{C}$ \\
\hline Pre-flight tests & March, $29^{\text {th }}$ & $06: 30 \mathrm{~h}$ & $00: 30 \mathrm{~h}$ & $\sim+21^{\circ} \mathrm{C}$ \\
\hline Refrigeration of the Irradiator with the bacterial strains & March, $29^{\text {th }}$ & 07:00 h & $01: 00 \mathrm{~h}$ & $\sim+10^{\circ} \mathrm{C}$ \\
\hline Boarding the apparatus in the Soyus TMA- 8 & March, $29^{\text {th }}$ & $12: 20 \mathrm{~h}$ & $06: 20 \mathrm{~h}$ & $\sim+22$ to $+23^{\circ} \mathrm{C}$ \\
\hline Lauching of Soyus TMA- 8 & March, $30^{\text {th }}$ & $02: 30 \mathrm{~h}$ & $20: 30 \mathrm{~h}$ & $\sim+22$ to $+23^{\circ} \mathrm{C}$ \\
\hline Soyus TMA 8 docked to the ISS & April, $1^{\text {st }}$ & $04: 18 \mathrm{~h}$ & 2 days $+22: 18 \mathrm{~h}$ & $\sim+21^{\circ} \mathrm{C}$ \\
\hline Begin of UV-A irradiation & April, $7^{\text {th }}$ & $13: 40 \mathrm{~h}$ & 9 days $+07: 40 \mathrm{~h}$ & $\sim+21^{\circ} \mathrm{C}^{*}$ \\
\hline End of UV-A irradiation & April, $7^{\text {th }}$ & $17: 40 \mathrm{~h}$ & 9 days $+11: 40 \mathrm{~h}$ & $\sim+21^{\circ} \mathrm{C}^{*}$ \\
\hline Soyus TMA 7 undocked from the ISS & April, $8^{\text {th }}$ & $20: 23 \mathrm{~h}$ & 10 days $+14: 23 \mathrm{~h}$ & $\sim+21^{\circ} \mathrm{C}$ \\
\hline Reentry at Earth's atmosphere & April, $8^{\text {th }}$ & $23: 47 \mathrm{~h}$ & 10 days $+17: 47 \mathrm{~h}$ & $\sim+25^{\circ} \mathrm{C}$ \\
\hline Delivery of the apparatus to the research team at Moscow & April, $9^{\text {th }}$ & $08: 00 \mathrm{~h}$ & 11 days $+02: 00 \mathrm{~h}$ & $\sim+10$ to $+25^{\circ} \mathrm{C}$ \\
\hline Begin of survival and mutagenesis tests & April, $9^{\text {th }}$ & $12: 40 \mathrm{~h}$ & 11 days $+06: 40 \mathrm{~h}$ & $\sim+25^{\circ} \mathrm{C}$ \\
\hline
\end{tabular}

${ }^{*}$ ] a maximum, of short duration, $+30^{\circ} \mathrm{C}$ was reached inside the irradiation module, during the 4 hours of irradiation. 


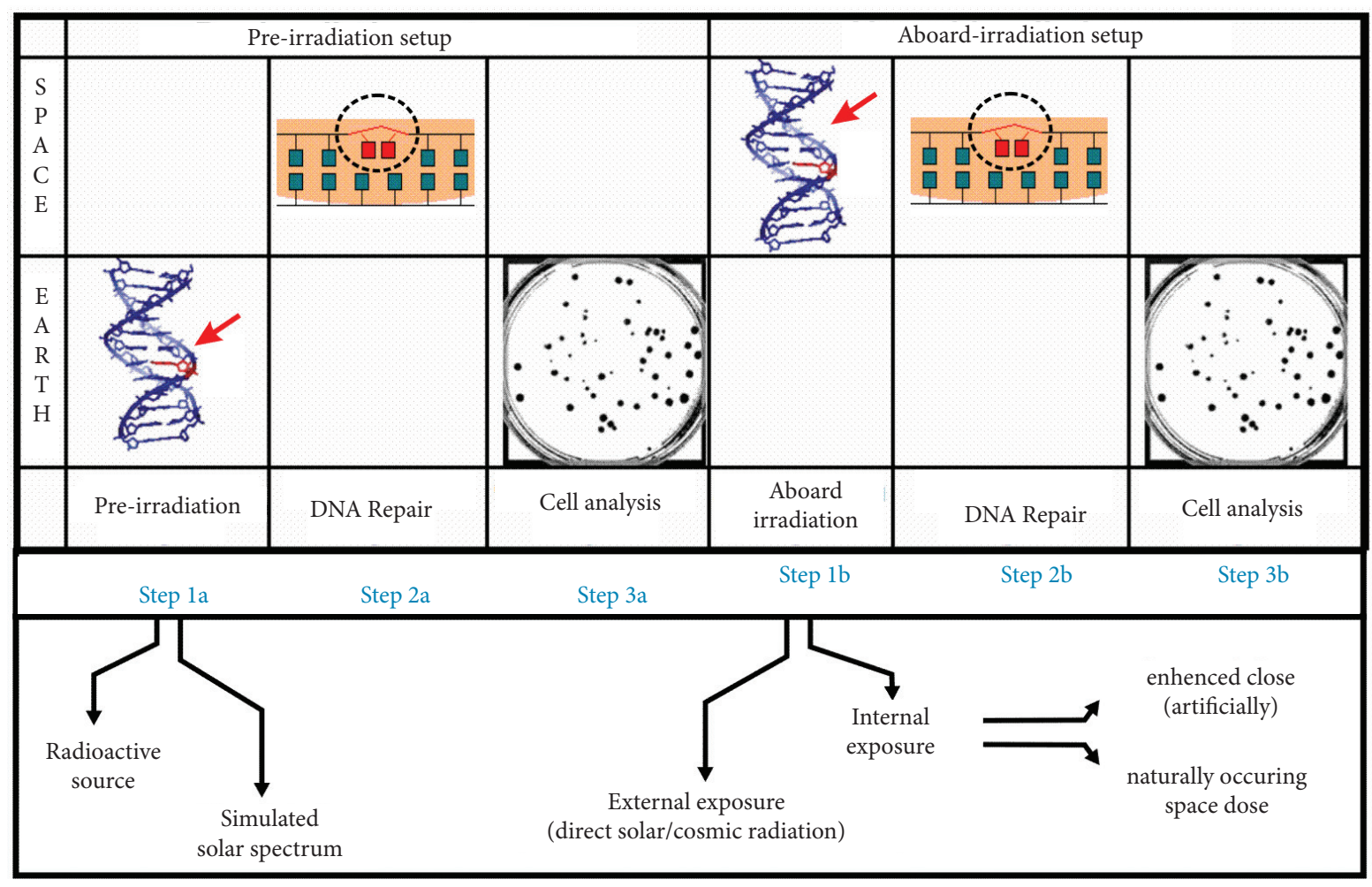

Figure 6. "Classical setup" for DNA repair experiments in microgravity (steps 1a-3a) and the in situ biological experiment (steps 1b-3b) during the USA-Russian-Brazil centenary flight mission in March-April 2006.

Allen belts, may also contribute to doses. During the flight experiment, we monitored the dose at the irradiation slots by two thermoluminescent solid state dosimeters: TLD-100 (LiF: Mg,Ti), measuring $3.2 \mathrm{~mm}$ x $3.2 \mathrm{~mm}$ x $0.9 \mathrm{~mm}$. The dosimetry based only on passive TLD detectors is not enough to describe the total interaction of ionizing radiations with the biological material on board the ISS, but may allow an indication of any abnormal radiation event occurring during the flight. The integrated effective dose for the $\sim 10$ days of flight was $3.7 \mathrm{mSv}$, if a mean radiation quality factor of 2.2 is assumed (Reitz et al., 1996). This value is slightly higher than the TLD dosimetric value (3.8 mSv during 15 days in orbit) obtained during the space experiment REPAIR and KINETICS, conducted by Horneck et al. (1996), performed during the IML-2 mission in July 1994 (also during a period of solar minimum). In addition, during the present mission, solar $\mathrm{X}$-ray emissions detected by the GOES satellite did not registered any important enhancement related to solar events higher than a C 9.0 flares (correspondent to a peak flux of $9 \times 10^{-6} \mathrm{~W} \cdot \mathrm{m}^{-2}$, in the 1-8 A energy channel). During the hours that the UV-A radiation was induced in the experiment, only a B5.0 solar flare was measured by the GOES detectors, which is considered a minor event (correspondent to a peak flux of $5 \times 10^{-7} \mathrm{~W} \cdot \mathrm{m}^{-2}$ ). Moreover, there was not report any CME event or anomalous galactic cosmic ray flux interacting with the earth. In short, there was no relevant anomaly in the parameters that characterize the geo-space behavior during the experiment.

\section{RESULTS AND DISCUSSION}

The analysis of the ionizing irradiation carried out during ISS orbit, the performance of the CIM system, and the results of the biological experiment follow.

Memory Module data results: After an analysis of Irradiance follow-up data stored in the MM, it was noted that the sets of LEDs in the two slots turned off after 25 minutes, contrary to the 240 minutes programmed in the firmware, due to an undetermined 
failure. The temperature data for the EM was coherent with this observation, showing an inflection at 25 minutes into the recording, as shown in Fig. 7 (T3 - EM cover temperature).

Since the EM did not return to Earth, and the IM did not present any signs of failure in later tests carried out with the engineering model of the EM and firmware from the flight, nor were any problems found after a detailed analysis of the electronic circuits, watchdog registers and firmware design, we suspect there was a momentary failure due to radiation in the environment, such as SCR - Solar Cosmic Rays and GCR - Galactic Cosmic Rays, creating a SEU (Single Event Upset), associated with the use of COT components of medium-scale integration. Electronic failures of the ISS orbit are generally due to proton flow from the South Atlantic Anomaly- (SAA) (Kuznetsov, 2005). It was not possible to correlate the time of failure (April 7, 2006, 14:06 GMT) with the possible passage of the ISS through the SSA, in virtue of limited access to orbital data. Considering the mean UV irradiance value found for each slot was $4.38 \mathrm{~mW} . \mathrm{cm}^{-2}$, and the time the LEDs were turned on, the irradiation dose for the $\mathrm{AB} 1157$ and $\mathrm{P} 3478$ strains was $6.6 \mathrm{~J} . \mathrm{cm}^{-2}$ and the dose for the AB2463 and AB2480 strains was $63.6 \mathrm{~J} . \mathrm{cm}^{-2}$.

Observed biological response to UV-A radiation in a microgravity environment: In the experiment, the wild type strain (AB1157) and polA mutant (P3478) were irradiated with $6.6 \mathrm{~J} . \mathrm{cm}^{-2}$, while the strains uvrA recA (AB2480) and recA (AB2463) mutants followed the original irradiation protocol, with of $63.6 \mathrm{~J} . \mathrm{cm}^{-2}$. The above irradiation periods were recorded in the CIM memory module. Ground control experiments were conducted after the mission, employing the same irradiation module of the flight and similar irradiation periods and temperature conditions, as recorded. Considering the relative differences in survival frequency, the wild type strain (AB1157) was more sensitive onboard the ISS than on Earth. In contrast, the uvrA recA mutant (AB2480) was more resistant on ISS than on Earth. It has been reported that UV-A induces high quantities of cyclobutane pirimidine dimmers (CPD), which are lesions repaired via NER (Tyrrell, 1973; Douki et al., 2003 and Rochette et al., 2003). On the other hand, the uvrA recA mutant (AB2480) lacking NER would produce less DNA breaks than the wild type strain. In contrast, on Earth, where there are relatively lower doses of environmental ionizing radiation, the uvrA recA mutant was more sensitive than the wild type strain, since the absence of NER can represent a severe injury to the cells. The AB2463 ( recA) and P3478 (polA) strains did not show different results in UV-bacterial survival experiments carried out on Earth or on ISS. With the exception of the wild type strain (AB1157), the mutants presented higher or equivalent "spontaneous

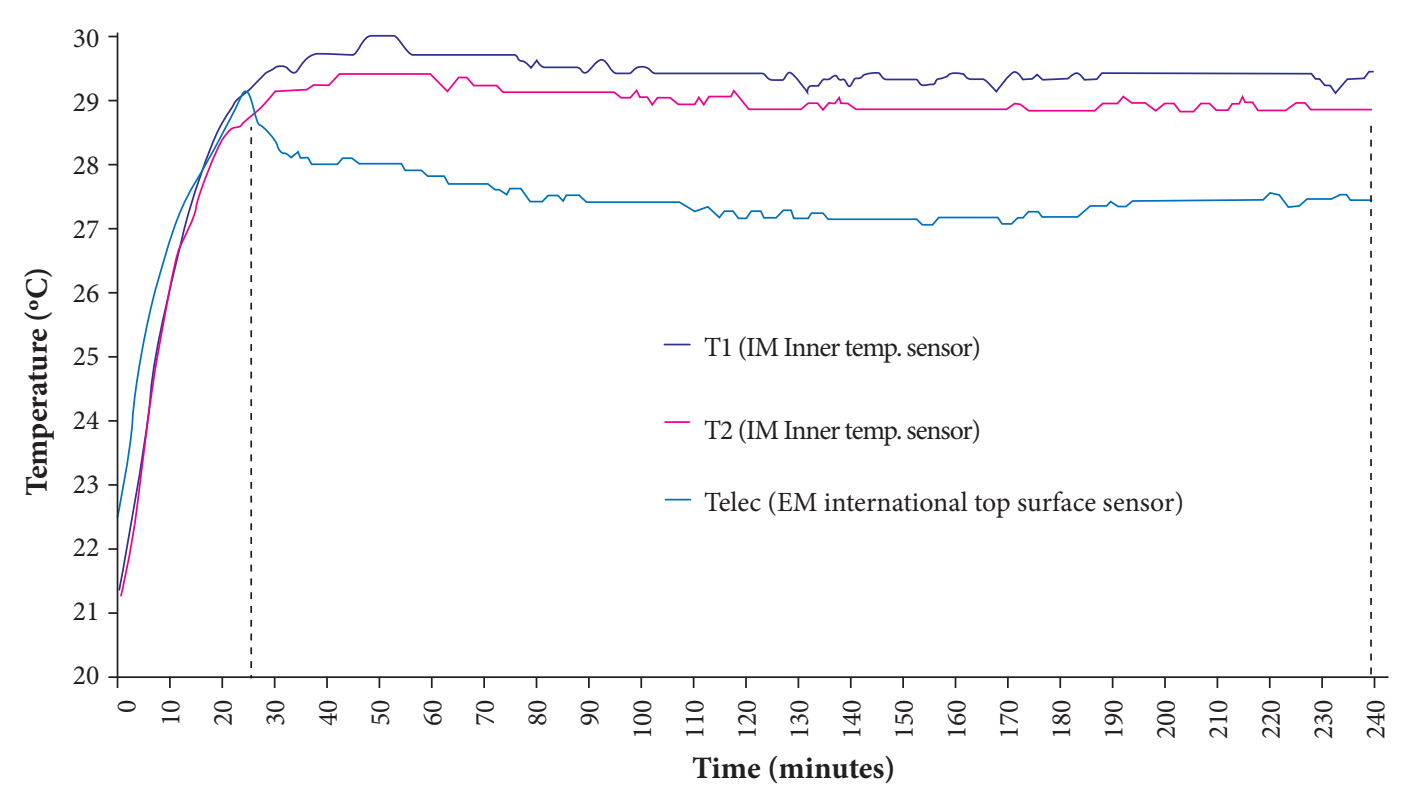

Figure 7. Temperature data during DRM experiment in the ISS. (T1) Irradiator module upper half, (T2) Irradiator module Botom half and the internal top surface (Telec) of the Electronic module. 
mutation" frequency on ISS. This could be explained by the elevated doses of cosmic radiation on ISS. Nevertheless, when irradiated by UV-A on ISS, the wild type strain (AB1157) and uvrA recA mutant (AB2480) decreased in mutation frequency. Taking into account that UV-A inhibits the protein synthesis, leading to cell growth delay (Favre et al., 1985), this agent could inhibit mutagenesis due to the local ionizing radiation, probably through blocking the DNA-replication, which would suppress the expression of the mutant phenotype. Yet, polA (P3478) and recA (AB2463) mutants presented growth delay when irradiated with UV-A. This effect would not interfere on mutation frequency of these strains.

\section{CONCLUSIONS}

The reduction of environment radiation effects on electronic devices should be better evaluated in a future version of this experiment. Techniques, such as redundancy and the use of components that are less susceptible to SEE, should be employed as Dodd and Massengill (2003) and LaBel et al. (1996) experiments conclusions. The irradiance modeling of the CIM irradiation wells, displayed in "UV irradiance", is of fundamental importance for future comparisons (even if in other systems) with the results obtained in the DRM experiment. Moreover, the techniques used in the modeling may be employed for other geometries and other, more powerful types of LEDs already on the market. In the microgravity experiment we could observe that, besides the environmental high cosmic ionizing radiation, compared to conditions on Earth, the induced UV-A irradiation could inhibit mutagenesis, probably because it inhibits the protein synthesis, leading to cell growth delay. Yet, polA (P3478) and recA (AB2463) presented growth delay when irradiated with UV-A. Nevertheless, these results suggest that more experiments would be conducted using the above experimental conditions in order to better understand the biological responses under high elevated irradiation environments.

\section{ACKNOWLEDGMENTS}

The authors are grateful to the Brazilian Space Agency (AEB) under Microgravity Program for sponsoring this project and to the Instituto de Aeronáutica e Espaço (IAE) and Instituto Nacional de Pesquisas Espaciais (INPE), especially the Engineers Agnaldo Eras, Narli B. Lisboa and Dilmar Vieira dos Santos for their great help in the development of the instrumentation; we also thank the Brazilian astronaut Marcos Cesar Pontes, who performed the Brazilian experiment aboard the ISS, and the technical and scientific staff of the Laboratório de Integração e Testes (LIT) from INPE, who provided the performance tests and, finally, the technical staff of ENERGIA, who clarified several details on building an onboard experiment in the ISS.

\section{REFERENCES}

Cogoli, A., 1996, "Biology under microgravity conditions in Spacelab International Microgravity Laboratory 2 (IML-2)", Journal of Biotechnology, Vol. 47, No 2-3, pp. 67-70. doi: 10.1016/0168-1656(96)01413-7.

Dodd, P. E. and Massengill, L.W., 2003, "Basic Mechanisms and Modeling of Single-Event Upset in Digital Microelectronics", IEEE Transactions on Nuclear Science, Vol. 50, No 3, pp. 583-602. doi: 10.1109/TNS.2003.813129.

Douki, T., Reunaud-Angelin, A., Cadet, J. and Sage, E., 2003, "Bipyrimidine photoproducts rather than oxidative lesions are the main type of DNA damage involved in the genotoxic effect of solar UVA radiation", Biochemistry, Vol. 42, No 30, pp. 9221-9226. doi: 10.1021/biO34593c.

Favre, A., Hajnsdorf, E., Thiam, K. and Araujo, A.C., 1985 , "Mutagenesis and growth delay induced in Escherichia coli by nearultraviolet radiations", Biochimie, Vol. 67, Issue 3-4, pp. 335-342. doi: 10.1016/S0300-9084(85)80076-6.
Horneck, G., Rettberg, P., Baumstark-Khan, C., Rink, H., Kozubek, S., Schäfer, M. and Schmitz, C., 1996, "DNA repair in microgravity: studies on bacteria and mammalian cells in the experiments REPAIR and KINETICS", Journal of Biotechnology, Vol. 47, No 2-3, pp 99-112.

Kiefer, J. and Pross, H.D., 1999, "Space radiation effects and microgravity”, Mutation Research, Vol. 430, Issue 2, pp. 299-305. doi:10.1016/S0027-5107(99)00142-6.

Kobayashi, Y., Kikuchi, M., Nagaoka, S. and Watanabe, H.,1996, "Recovery of Deinococcus radiodurans from radiation damage was enhanced under microgravity", Biological Sciences in Space, Vol. 10, No 2, pp. 97-101. doi:10.2187/bss.10.97.

Kobayashi, Y., Watanabe, H., Kikuchi, M. and Narumi, I., 2000, "Effect of the space environment on the induction of DNA-repair related proteins and recovery from radiation damage", Advances in Space Research, Vol. 25, No 10, pp. 2103-2106. 
Kuznetsov, N. V., 2005, "The Rate of Single Event Upsets in Electronic Circuits onboard Spacecraft", Cosmic Research, Vol. 43, No 6, pp. 443-451. doi:10.1007/s10604-005-0066-9.

LaBel, K. A., Gates, M.M., Moran, A.K., Marshall, P.W., Barth, J., Stassinopoulos, E.G., Seidleck, C.M. and Dale, C.J., 1996, "Commercial Microelectronics Technologies for Applications in the Satellite Radiation Environment", In: Proceedings Aerospace Applications Conference, Vol. 1, pp. 375-390. doi: 10.1109/AERO.1996.495897.

Manti, L., 2006, "Does reduced gravity alter cellular response to ionizing radiation?", Radiation and Environmental Biophysics, Vol. 45, No 1, pp. 1-8. doi: 10.1007/s00411-006-0037-4.

Nicholson, L.W., Ricco, A.J., Agasid, E., Christopher, B., Diaz-Aguado, M., Ehrenfreund, P., Friedricks, C., Ghassemieh, S., Henschke, M. Hines, J.W., Kitts, C., Luzzi, E., Ly, D., Mai, N., Mancinelli, R., McIntyre, M., Minelli, G., Neumann, M., Parra, M., Piccini, M., Rasay, M.R., Ricks, R., Santos, O., Schooley, A., Squires, D., Timucin, L., Yost, B. and Young, A., 2011, "The 0/OREOS Mission: First Science Data from the Space Environment Survivability of Living Organisms (SESLO) Payload", Astrobiology, Vol. 11, No 10, pp. 951-958. doi: 10.1089/ast.2011.0714.

Ottolenghi, A., Ballarini, F. and Biaggi, M., 2001, "Mechanistic bases for modelling space radiation risk and planning radiation protection of astronauts", Physica Medica, Vol. 17, Suppl 1, pp. 272-277.

Olsson-Francis, K. and Cockell, C.S., 2010, "Experimental methods for studying microbial survival in extraterrestrial environments", Journal of Microbiological Methods, Vol. 80, pp. 1-13. doi:10.1016/j.mimet.2009.10.004.

Pross, H.D., Kost. And Kiefer, J., 1994, "Repair of radiation induced genetic damage under microgravity", Advances in Space Research, Vol. 14, Issue 10, pp. 125-130. doi:10.1016/0273-1177(94)90461-8.

Pross, H.D., and Kiefer, J., 1999, "Repair of cellular radiation damage in space under microgravity conditions", Radiation and Environmental Biophysics, Vol. 38, No2, pp. 133-138. doi:10.1007/s004110050149.

Pross, H.D., Casares, A. and Kiefer, J., 2000, "Induction and Repair of DNA Double-Strand Breaks under Irradiation and Microgravity", Radiation Research, Vol. 153, No 5 Pt 1, pp. 521-525.

Reitz, G., Beaujean, R., Benton, E., Burmeister, S., Dachev, Ts., Deme, S., Luszik-Bhadra, M. and Olko, P., 2005, "Space radiation measurements on-board ISS-the DOSMAP experiment", Radiation Protection Dosimetry, Vol. 116, No 1-4 Pt 2, pp. 374-379. doi:10.1093/rpd/nci262.

Reitz, G., Beaujean, R., Kopp, M., Leicher, M. and Strauch, K., 1996, "Dosimetric mapping in BIORACK on IML2", Journal of Biotechnology, Vol. 47, Issue 2-3, pp. 83-88. doi: 10.1016/0168-1656(96)01372-7.

Rettberg, P., Eschweiler, U., Strauch, K., Reitz, G., Horneck, G., Wänke, H., Brack, A. and Barbier, B., 2002, "Survival of Microorganisms in space protected by Meteorite material: Results of the experiment 'EXOBIOLOGIE' of the Perseus mission", Advances in Space Research, Vol. 30, No 6, pp. 1539-1545. doi: 10.1016/SO273-1177[02]00369-1.
Rochette, P.J., Therrien, J.P., Drouin, R., Perdiz, D., Bastien, N., Drobetsky, E.A. and Sage, E., 2003, "UVA-induced ciclobutane pyrimidine dimers from predominantly at thymine dipyrimidine and correlate with the mutation spectrum in rodent cells", Nucleic Acids Research, Vol. 31, No 11, pp. 2786-2794.

Sampaio, M., 2007, "Design, Dosimetry and performance of a UV irradiator system used in space biology", Ph.D. Thesis, Technological Institute of Aeronautics, São José dos Campos, Brazil, 158p. (In Portuguese).

Saffary, R., Nandakumar, R., Spencer, D., Robb, F.T., Davila, J.M., Swartz, M., Ofman, L., Thomas, R.J. and DiRuggiero, J., 2002 , "Microbial survival of space vacuum and extreme ultraviolet irradiation: strain isolation and analysis during a rocket flight", FEMS Microbiology Letters, Vol. 215, No 1, pp. 163-168.

SSP41163, 1999, "International Space Station Program: Russian Segment Specification, Revision G. National Aeronautics and Space Administration \& Russian Space Agency", Houston, Texas, USA \& Moscow, Russia, $452 \mathrm{pp}$.

SSP50094, 2000, "NASA/RSA JOINT SPECIFICATIONS: Standards Document for the ISS: Russian Segment. Revision A. National Aeronautics and Space Administration \& Russian Space Agency", Houston, Texas, USA \& Moscow, Russia, 532 pp.

SSP50146, 1998, "NASA/RSA Bilateral Safety and Mission Assurance Process Requirements for the ISS Revision A. National Aeronautics and Space Administration \& Russian Space Agency", Houston, Texas, USA \& Moscow, Russia, 159 pp.

Takahashi, A., Ohnishi, K., Takahashi, S., Masukawa, M., Sekikawa, K., Amano, T., Nakano, T., Nagaoka, S. and Ohnishi, T., 2001, "The effects of microgravity on induced mutation in Escherichia coli and Saccharomyces cerevisiae", Advances in Space Research, Vol. 28, Issue 4, pp. 555-561. doi: 10.1016/S0273-1177(01)00391-X.

Takahashi, A., Suzuki, H., Omori, K., Seki, M., Hashizume, T., Shimazu, T., Ishioka, N. and Ohnishi, T., 2011, "Expression of p53-regulated genes in human cultured lymphoblastoid TSCE5 and WTK1 cell lines after spaceflight in a frozen state", Advances in Space Research, Vol. 47, Issue 6, pp. 1062-1070. doi: 10.1016/j.asr.2010.11.002.

Tyrrell, R.M., 1973, "Induction of pyrimidine dimers in bacterial DNA by $365 \mathrm{~nm}$ radiation", Photochemistry and Photobiology, Vol. 17, Issue 1, pp. 69-73. doi: 10.1111/j.1751-1097.1973.tb06334.x.

Yatagai, F., Honma, M., Ukai, A., Omori, K., Suzuki, H., Shimazu, T., Takahashi, A., Ohnishi, T., Dohmae, N. and Ishioka, N., 2012, "Preliminary results of space experiment: Implications for the effects of space radiation and microgravity on survival and mutation induction in human cells", Advances in Space Research, Vol. 49, Issue 3, pp. 479-486. doi: 10.1016/j.asr.2011.10.015.

Yi, Z.C., Li, X.F., Wang, Y., Wang, J., Sun, Y. and Zhuang, F.Y., 2011, "The postmitotic Saccharomyces cerevisiae after spaceflight showed higher viability", Advances in Space Research, Vol. 47, Issue 11, pp. 2049-2057. doi:10.1016/j.asr.2011.02.006. 